\title{
Malassezia nana sp. nov., a novel lipid-dependent yeast species isolated from animals
}

\author{
Correspondence \\ Rui Kano \\ kano@brs.nihon-u.ac.jp
}

\author{
Asuka Hirai, ${ }^{1}$ Rui Kano, ${ }^{1}$ Koichi Makimura, ${ }^{2}$ Eduardo Robson Duarte, ${ }^{3}$ \\ Júnia Soares Hamdan, ${ }^{3}$ Marc-André Lachance, ${ }^{4}$ Hideyo Yamaguchi $^{2}$ \\ and Atsuhiko Hasegawa ${ }^{1}$
}

\author{
${ }^{1}$ Department of Pathobiology, Nihon University School of Veterinary Medicine, Kameino, \\ Fujisawa, Kanagawa 252-8510, Japan \\ ${ }^{2}$ Teikyo University Institute of Medical Mycology, Otsuka, Hachioji, Tokyo 192-0395, Japan \\ ${ }^{3}$ Department of Microbiology, Biological Science Institute, Federal University of Minas Gerais, \\ Avenida Antonio Carlos, Belo Horizonte, Minas Gerais, 31270-901, Brazil
}

${ }^{4}$ Department of Biology, University of Western Ontario, London, Ontario, Canada N6A 5 B7

\begin{abstract}
Five isolates of a novel species of the yeast genus Malassezia were isolated from animals in Japan and Brazil. Phylogenetic trees based on the D1/D2 domains of the large-subunit (26S) rDNA sequences and nucleotide sequences of the internal transcribed spacer 1 region showed that the isolates were conspecific and belonged to the genus Malassezia. They were related closely to Malassezia dermatis and Malassezia sympodialis, but were clearly distinct from these two species and the other six species of Malassezia that have been reported, indicating that they should be classified as a novel species, Malassezia nana sp. nov. Morphologically and physiologically, $M$. nana resembles $M$. dermatis and $M$. sympodialis, but can be distinguished from these species by its inability to use Cremophor EL (Sigma) as the sole lipid source and to hydrolyse aesculin. The type strain of $M$. nana is NUSV $1003^{\top}\left(=\mathrm{CBS}_{9557^{\top}}=\mathrm{JCM} 12085^{\top}\right)$.
\end{abstract}

Malassezia species have been recognized as members of the microbiological flora of human and animal skin; they are also considered to be aetiological agents of pityriaris versicolor and Malassezia folliculitis in humans (Ashbee \& Evans, 2002) and otitis externa in dogs. Malassezia pachydermatis and Malassezia sympodialis have been isolated from cats with otitis externa (Greene, 1998; Crespo et al., 2000), whilst Malassezia globosa, Malassezia furfur, Malassezia slooffiae and M. sympodialis have been isolated from cattle with otitis externa (Duarte et al., 1999, 2001).

The genus Malassezia includes lipophilic and globose to subglobose or ellipsoidal yeasts with monopolar budding (Boekhout, 1998). These species can be identified by morphological, biochemical and molecular characteristics (Guillot \& Guého, 1995; Guého et al., 1996). Molecular typing methods have also been applied to these species (Boekhout et al., 1998; Senczek et al., 1999; Gupta et al.,

Published online ahead of print on 1 August 2003 as DOI 10.1099/ ijs.0.02776-0.

Abbreviation: ITS1, internal transcribed spacer 1.

The GenBank/EMBL/DDBJ accession numbers for the 26S rDNA sequences reported in this paper are AB075224, AB105860$A B 105862$ and $A Y 166596$, and the accession numbers for the ITS1 region sequences are AB075223 and AB105863.
2000; Theelen et al., 2001; Gaitanis et al., 2002; Gemmer et al., 2002). Sequences of the D1/D2 domains of the large-subunit (26S) rDNA and nucleotide sequences of the internal transcribed spacer 1 (ITS1) region, which is located between $18 \mathrm{~S}$ and $5 \cdot 8 \mathrm{~S}$ rDNA, have been utilized for the examination of these species (Fell et al., 2000; Makimura et al., 2000). Kano et al. (1999) and Aizawa et al. (1999, 2001) also sequenced and analysed the chitin synthase 2 gene of seven species of Malassezia, in order to understand their phylogenetic relationships.

Recently, an eighth species of Malassezia, newly isolated from the skin of a human with atopic dermatitis, was described as Malassezia dermatis by using molecular analysis (Sugita et al., 2002). As a result of molecular analysis, we suggested that an isolate from a cat might belong to a novel species of the genus Malassezia (Hirai et al., 2002). Moreover, four other isolates from cows were revealed to be conspecific with that isolate. The present study describes these five isolates as a novel species of Malassezia, for which the name Malassezia nana sp. nov. is proposed.

The origins of the novel isolates discussed in this study are given in Table 1 . NUSV $1003^{\mathrm{T}}$ was isolated from a cat with otitis externa in Hyogo, Japan (Hirai et al., 2002). Modified Dixon (mDixon) agar was inoculated with discharge from the ear (Guého et al., 1996) and incubated at $32^{\circ} \mathrm{C}$ for 
Table 1. Origins of strains of $M$. nana

\begin{tabular}{|lll|}
\hline Strain & \multicolumn{1}{c|}{ Origin } & Place of isolation \\
\hline NUSV $1003^{\mathrm{T}}$ & Cat (otitis externa) & Hyogo, Japan \\
VG Luz 776 & Cow (otitis externa) & Minas Gerais, Brazil \\
VG Luz 979 & Cow (otitis externa) & Minas Gerais, Brazil \\
VSF Geleia & Cow (normal ear canal) & Minas Gerais, Brazil \\
VM Pom Passarela & Cow (normal ear canal) & Minas Gerais, Brazil \\
\hline
\end{tabular}

1 week. The other four isolates were isolated from cerumen or ear discharges from cows, two of which had otitis externa and two of which were healthy, in farms at Minas Gerais, Brazil. These specimens were inoculated onto Mycosal agar medium (Difco) that was modified by addition of glucose (final concentration, 4\%) and chloramphenicol (final concentration, $150 \mathrm{mg} \mathrm{l}^{-1}$ ), olive oil having been added to the surface of the medium; the medium was then incubated at $32{ }^{\circ} \mathrm{C}$ for 1 week.

Isolates were cultured on mDixon agar and Sabouraud's dextrose agar at $32{ }^{\circ} \mathrm{C}$ for 1 week and were then analysed morphologically and biologically as descibed by Guého et al. (1996) and Hagler \& Ahearn (1981). Furthermore, utilization of the polyoxyethylated castor oil Cremophor EL (Sigma), hydrolysis of aesculin (Mayser et al., 1997) and precipitate production on mDixon agar (Hammer \& Riley, 2000) were also examined.

Morphological and physiological characteristics of the five isolates were similar in many ways to those of $M$. sympodialis and M. dermatis (Guého et al., 1996; Sugita et al., 2002); however, the isolates can be distinguished from these two species by their inability to use Cremophor EL as the sole lipid source and to hydrolyse aesculin (Table 2). In terms of morphology, cells were comparatively small $(1 \cdot 5-2 \cdot 0 \times 2 \cdot 5-3 \cdot 0 \mu \mathrm{m})$ (Guého et al., 1996). Because of this morphological characteristic, we propose the name $M$. nana for the isolates.

Yeast cells were collected by scraping colonies from the surface of the agar plate. High-molecular-mass DNA was obtained from these cells by phenol/chloroform extraction. Samples were dissolved in TE buffer $(10 \mathrm{mM}$ Tris/ $\mathrm{HCl}$, $1 \mathrm{mM}$ EDTA, $\mathrm{pH} \mathrm{8.0)}$ and used for PCR amplification (Kano et al., 1999; Aizawa et al., 1999, 2001). Some D1/ D2 rDNA sequences were also obtained by direct amplification from whole cells (Lachance et al., 1999).

Sequences of degenerate primers for 26S rDNA amplification were based on the sequences reported by Fell et al. (2000) (forward primer, F63: 5' -GCATATCAATAAGCGGAGGAAAAG-3'; reverse primer, LR3: 5'-GGTCCGTGTTTCAAGACG-3'). PCR amplification of 265 rDNA was carried out for 35 cycles, each of which consisted of template denaturation $\left(1 \mathrm{~min}\right.$ at $\left.94^{\circ} \mathrm{C}\right)$, primer annealing $\left(2 \mathrm{~min}\right.$ at $\left.55^{\circ} \mathrm{C}\right)$ and polymerization $\left(2 \mathrm{~min}\right.$ at $\left.72^{\circ} \mathrm{C}\right)$.

Sequences of degenerate primers for the ITS1 region were the same as described previously (forward primer, 18SF1: 5'-AGGTTTCCGTAGGTGAACCT-3'; reverse primer, 58SR1: 5' -TTCGCTGCGTTCTTCATCGA-3'; Makimura et al., 2000). PCR amplification of the ITS1 region was carried out for 25 cycles, each of which consisted of template

Table 2. Characteristics of M. nana and other Malassezia species

Species: 1, M. nana sp. nov.; 2, M. furfur; 3, M. pachydermatis; 4, M. sympodialis; 5, M. globosa; 6, M. obtusa; 7, M. restricta; 8, M. slooffiae; 9, M. dermatis. Data are from Guého et al. (1996), Mayser et al. (1997), Hammer \& Riley (2000) and Midgley (2000). +, Positive; +/-, weakly positive; -, negative; v, variable; NT, not tested.

\begin{tabular}{|c|c|c|c|c|c|c|c|c|c|}
\hline Characteristic & 1 & 2 & 3 & 4 & 5 & 6 & 7 & 8 & 9 \\
\hline Growth on Sab..$^{*}$ at $32{ }^{\circ} \mathrm{C}$ & - & - & + & - & - & - & - & - & - \\
\hline Growth on mDixon at $40^{\circ} \mathrm{C}$ & + or - & + & + & + & - & - & - & + & + \\
\hline \multicolumn{10}{|l|}{ Use of lipid sources: } \\
\hline Tween $20(10 \%)$ & + or - & + & - & - & - & - & - & $+1-$ or + & + \\
\hline Cremophor EL & - & + & $\mathrm{V}$ & - & - & - & - & - & + \\
\hline Hydrolysis of aesculin & - & - & $\mathrm{V}$ & + & - & + & - & - & - \\
\hline Precipitate production on mDixon agar & + & - & NT & + & + & - & NT & - & + \\
\hline
\end{tabular}

*Sabouraud's agar without any lipid supplementation. 
denaturation $\left(1 \mathrm{~min}\right.$ at $\left.94{ }^{\circ} \mathrm{C}\right)$, primer annealing $(15 \mathrm{~s}$ at $60{ }^{\circ} \mathrm{C}$ ) and polymerization $\left(15 \mathrm{~s}\right.$ at $\left.72{ }^{\circ} \mathrm{C}\right)$. PCR products were electrophoresed through $2 \%$ agarose gel and then stained with ethidium bromide.

Each PCR product was cloned into a plasmid vector and more than three clones from each sample were sequenced according to methods described previously (Kano et al., 1999; Aizawa et al., 1999, 2001). To examine phylogenetic relationships, we used the neighbour-joining method with the CLUSTAL $\mathrm{W}$ multiple sequence alignment program (Thompson et al., 1994); a phylogenetic tree was constructed by using TREEVIEW for displaying phylogenies (Page, 1996). Bootstrap analysis was performed on 1000 random samples taken from multiple alignments, as described by Felsenstein (1985).

Nucleotide sequence analysis of the 26S rDNA (D1/D2 regions) of these isolates showed fewer than five substitutions over $577 \mathrm{bp}$ among them; the isolates differed by $>23$ substitutions over $577 \mathrm{bp}$ from the eight Malassezia species that have been reported previously (Fell et al., 2000; Sugita et al., 2002). The difference between these isolates and the eight Malassezia species exceeded that generally observed between species (Scorzetti et al., 2002). Phylogenetic analysis of $26 \mathrm{~S}$ rDNA sequences from these isolates showed that they were conspecific and were clearly distinct from the other eight Malassezia species, although they were related closely to M. dermatis and M. sympodialis (Fig. 1).

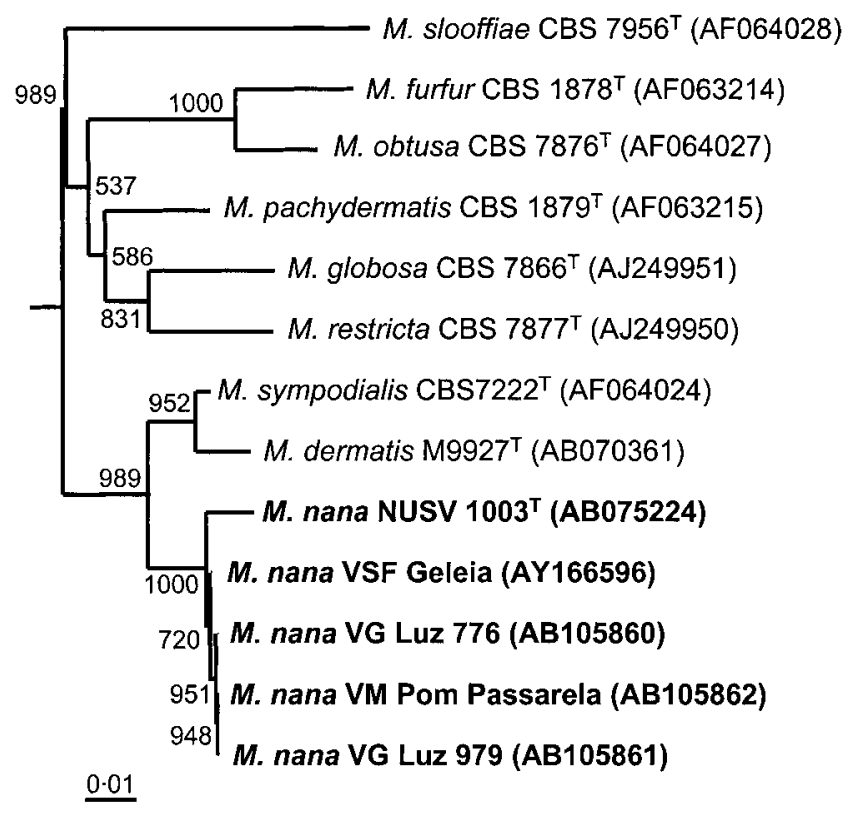

Fig. 1. Phylogenetic relationships of $M$. nana and eight recognized Malassezia species, based on the D1/D2 region of 26S rDNA sequences. The tree was constructed as described in the text. Numbers at nodes are bootstrap frequencies derived from 1000 replicates. GenBank accession numbers are shown in parentheses. Bar, 0.01 nucleotide substitutions per site.
Nucleotide sequence analysis of the ITS1 region of these isolates showed fewer than four substitutions over $182 \mathrm{bp}$ between them, and $>27$ substitutions over 158 bp with respect to the sequences of the eight Malassezia species reported previously (Makimura et al., 2000; Sugita et al., 2002). Our paper on phylogenetic analyses of Malassezia species based on ITS1 DNA revealed that the sequences of members of this genus are exceptionally diverse (Makimura et al., 2000). Species identification and strain typing by using the ITS1 region were carried out by means of phylogenetic analysis; congeneric strains were shown to be grouped into identical clusters and are classified accordingly (Makimura et al., 2000). In phylogenetic analysis of the ITS1 region, these five isolates were shown to be conspecific and did not belong to any of the eight recognized Malassezia species; this is also the case for the phylogenetic analysis of $26 \mathrm{~S}$ rDNA sequences (Fig. 2) (Makimura et al., 2000; Sugita et al., 2002). These results indicate that these isolates belong to a novel species of Malassezia.

The two phylogenetic trees show that there are slight differences between NUSV $1003^{\mathrm{T}}$, the Japanese isolate, and the four Brazilian isolates. Furthermore, the phylogenetic tree of 26S rDNA showed that there was some divergence among these four Brazilian isolates. Thus, in M. nana, $26 \mathrm{~S}$ rDNA is more variable than the ITS1 region.

The five isolates examined are clearly conspecific, although the Japanese isolate was slightly different from the four Brazilian isolates in the phylogenetic trees. Therefore, the Japanese isolate was designated as the type strain, as it was the first to be suggested as a novel species of Malassezia (Hirai et al., 2002).

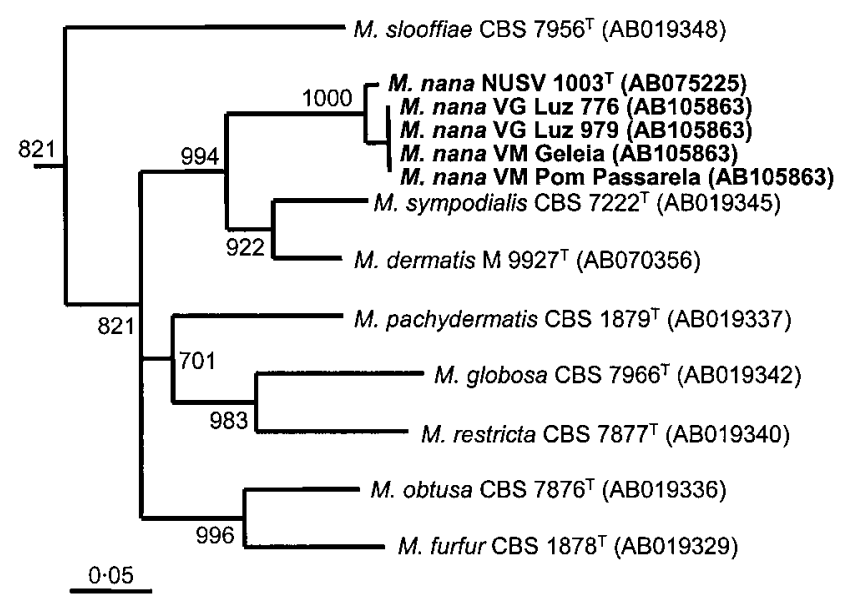

Fig. 2. Phylogenetic relationships of $M$. nana and eight recognized Malassezia species, based on ITS1 region sequences. The tree was constructed as described in the text. Numbers at nodes are bootstrap frequencies derived from 1000 replicates. GenBank accession numbers are shown in parentheses. Bar, 0.05 nucleotide substitutions per site. 


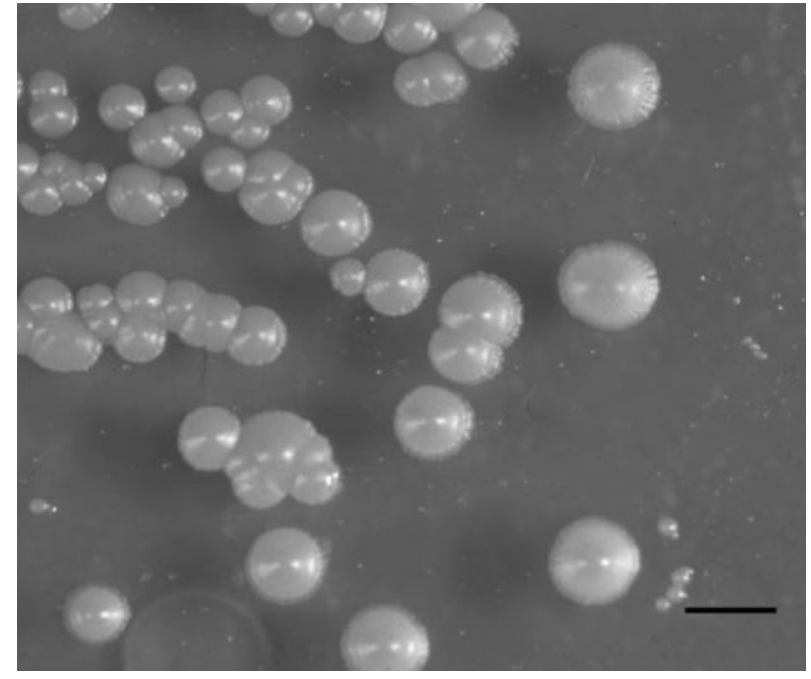

Fig. 3. $M$. nana NUSV $1003^{\top}$ cultured on mDixon agar at $32{ }^{\circ} \mathrm{C}$ for 1 week. Bar, $2 \mathrm{~mm}$.

As M. nana was isolated from a cat and cows with or without otitis externa, it was suggested as a member of the microbiological flora of animals, as for the other Malassezia species. Further studies are required to investigate whether $M$. nana plays a pathogenic role in otitis externa or other diseases of humans and animals.

\section{Latin diagnosis of Malassezia nana Hirai, Kano, Makimura, Yamaguchi et Hasegawa sp. nov.}

Coloniae in agaro Dixonii post 7 dies $32{ }^{\circ} \mathrm{C}$ nitentes aut hebetatae, leves, convexae ( $2 \mathrm{~mm})$. Textura molis. Cellulae ovoideae aut globosae $(1 \cdot 5-2 \cdot 0 \times 2 \cdot 5-3 \cdot 0 \mu \mathrm{m})$, e base angusta gemmantes. $\mathrm{H}_{2} \mathrm{O}_{2}$ hydrolysatur. Commutatio coloris per diazonium $B$ positiva. In agaro glucosi-peptonico Tween 40, Tween $60(0.5 \%)$ addito crescit, Tween $80(0.1 \%)$ addito hebdomadale crescit, Tween $20(10 \%)$ addito plerumque crescit, et Cremophor EL addito non crescit. Sectura aesculini negativa. In agaro Dixonii praecipitationis productio positiva. $37^{\circ} \mathrm{C}$ plerumque crescit. Teleomorphis ignotus. Typus NUSV $1003^{\mathrm{T}}$, ex felis otite externa, Hyogo, Japan, Martius 2001, $\mathrm{K}$. Yasuda isolatus est. In collectione zymotica Centraalbureau voor Schimmelcultures, Delphi Batavorum, CBS $9557^{\mathrm{T}}$ $\left(=\mathrm{JCM} 12085^{\mathrm{T}}\right)$ deposita est.

\section{Description of Malassezia nana Hirai, Kano, Makimura, Yamaguchi \& Hasegawa sp. nov.}

Malassezia nana (na'na. L. fem. n. nana a female dwarf; so named due to the organism's comparatively small cells).

After 1 week incubation on mDixon agar, colonies are cream to yellow, glistening to dull, smooth, convex and have a mean diameter of $2 \mathrm{~mm}$ (Fig. 3). Texture of colonies is soft and viscous. Microscopic examination reveals small, ovoid to globose $(1 \cdot 5-2 \cdot 0 \times 2 \cdot 5-3 \cdot 0 \mu \mathrm{m})$ cells with monopolar budding at the narrow end (Fig. 4). Catalase and

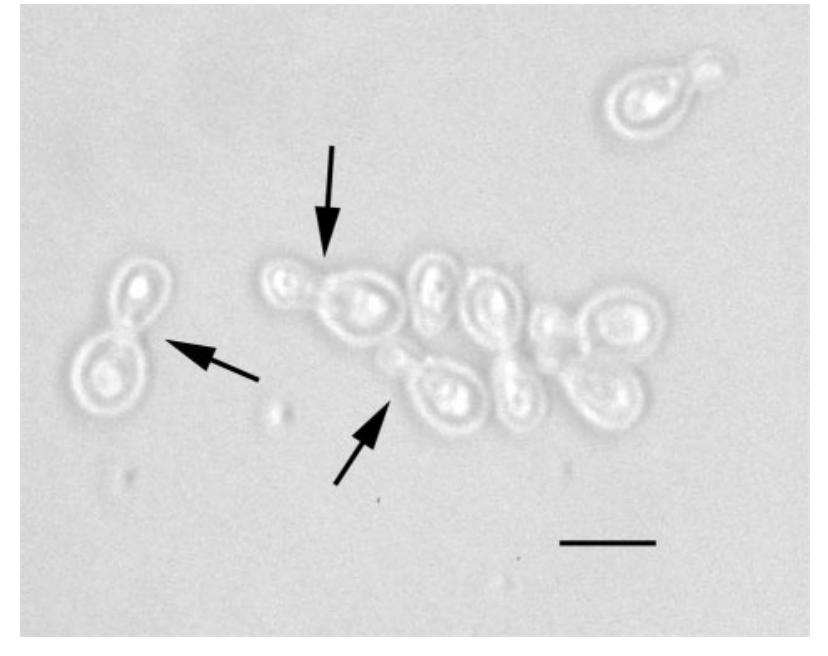

Fig. 4. Cells of $M$. nana NUSV $1003^{\top}$ are small and ovoid to globose with a narrow end. Arrows indicate monopolar budding. Bar, $3 \mu \mathrm{m}$.

diazonium blue $\mathrm{B}$ reactions are positive. No growth is obtained on Sabouraud's dextrose agar without lipid supplementation. Colonies develop on glucose-peptone agar supplemented with Tweens 40 or $60(0.5 \%)$, grow weakly on glucose-peptone agar supplemented with Tween $80(0 \cdot 1 \%)$ and usually grow on glucose-peptone agar supplemented with $10 \%$ Tween 20 . No growth is observed on glucose-peptone agar with Cremophor EL. Aesculin hydrolysis is negative. Precipitate production on mDixon agar is positive. Good growth usually occurs at $37^{\circ} \mathrm{C}$ (Table 2). Teleomorphs are unknown.

The type strain, NUSV $1003^{\mathrm{T}}\left(=\mathrm{CBS} 9557^{\mathrm{T}}=\mathrm{JCM} 12085^{\mathrm{T}}\right)$, was isolated from a cat with otitis externa in Hyogo, Japan, by K. Yasuda in March 2001 (Hirai et al., 2002). Reference strains are VG Luz 776 (=CBS 9558=JCM 12086), VG Luz 979 (=CBS 9559=JCM 12087), VSF Geleia ( = CBS 9560= JCM 12088) and VM Pom Passarela ( = CBS 9561= JCM 12089).

\section{References}

Aizawa, T., Kano, R., Nakamura, Y., Watanabe, S. \& Hasegawa, A. (1999). Molecular heterogeneity in clinical isolates of Malassezia pachydermatis from dogs. Vet Microbiol 70, 67-75.

Aizawa, T., Kano, R., Nakamura, Y., Watanabe, S. \& Hasegawa, A. (2001). The genetic diversity of clinical isolates of Malassezia pachydermatis from dogs and cats. Med Mycol 39, 329-334.

Ashbee, H. R. \& Evans, E. G. (2002). Immunology of diseases associated with Malassezia species. Clin Microbiol Rev 15, 21-57.

Boekhout, T. (1998). Diagnostic descriptions and key to presently accepted heterobasidiomycetous genera. In The Yeasts, a Taxonomic Study, 4th edn, p. 631. Edited by C. P. Kurtzman \& J. W. Fell. Amsterdam: Elsevier.

Boekhout, T., Kamp, M. \& Guého, E. (1998). Molecular typing of Malassezia species with PFGE and RAPD. Med Mycol 36, 365-372. 
Crespo, M. J., Abarca, M. L. \& Cabañes, F. J. (2000). Otitis externa associated with Malassezia sympodialis in two cats. J Clin Microbiol 38, 1263-1266.

Duarte, E. R., Melo, M. M., Hahn, R. C. \& Hamdan, J. S. (1999). Prevalence of Malassezia spp. in the ears of asymptomatic cattle and cattle with otitis in Brazil. Med Mycol 37, 159-162.

Duarte, E. R., Resende, J. C. P., Rosa, C. A. \& Hamdan, J. S. (2001). Prevalence of yeasts and mycelial fungi in bovine parasitic otitis in the state of Minas Gerais, Brazil. J Vet Med B Infect Dis Vet Public Health 48, 631-635.

Fell, J. W., Boekhout, T., Fonseca, A., Scorzetti, G. \& StatzellTallman, A. (2000). Biodiversity and systematics of basidiomycetous yeasts as determined by large-subunit rDNA D1/D2 domain sequence analysis. Int J Syst Evol Microbiol 50, 1351-1371.

Felsenstein, J. (1985). Confidence limits on phylogenies: an approach using the bootstrap. Evolution 39, 783-791.

Gaitanis, G., Velegraki, A., Frangoulis, E., Mitroussia, A., Tsigonia, A., Tzimogianni, A., Katsambas, A. \& Legakis, N. J. (2002). Identification of Malassezia species from patient skin scales by PCR-RFLP. Clin Microbiol Infect 8, 162-173.

Gemmer, C. M., DeAngelis, Y. M., Theelen, B., Boekhout, T. \& Dawson, T. L., Jr (2002). Fast, noninvasive method for molecular detection and differentiation of Malassezia yeast species on human skin and application of the method to dandruff microbiology. J Clin Microbiol 40, 3350-3357.

Greene, C. E. (1998). Clinical problems. In Infectious Diseases of the Dog and Cat, 2nd edn, pp. 549-554. Edited by C. E. Greene. Philadelphia, PA: W. B. Saunders.

Guého, E., Midgley, G. \& Guillot, J. (1996). The genus Malassezia with description of four new species. Antonie van Leeuwenhoek 69, 337-355.

Guillot, J. \& Guého, E. (1995). The diversity of Malassezia yeasts confirmed by rRNA sequence and nuclear DNA comparisons. Antonie van Leeuwenhoek 67, 297-314.

Gupta, A. K., Kohli, Y. \& Summerbell, R. C. (2000). Molecular differentiation of seven Malassezia species. J Clin Microbiol 38, 1869-1875.

Hagler, A. N. \& Ahearn, D. G. (1981). Rapid diazonium blue B test to detect basidiomycetous yeasts. Int J Syst Bacteriol 31, 204-208.

Hammer, K. A. \& Riley, T. V. (2000). Precipitate production by some Malassezia species on Dixon's agar. Med Mycol 38, 105-107.

Hirai, A., Kano, R., Makimura, K., Yasuda, K., Konishi, K., Yamaguchi, H. \& Hasegawa, A. (2002). A unique isolate of Malassezia from a cat. J Vet Med Sci 64, 957-959.
Kano, R., Aizawa, T., Nakamura, Y., Watanabe, S. \& Hasegawa, A. (1999). Chitin synthase 2 gene sequence of Malassezia species. Microbiol Immunol 43, 813-815.

Lachance, M.-A., Bowles, J. M., Starmer, W. T. \& Barker, J. S. (1999). Kodamaea kakaduensis and Candida tolerans, two new ascomycetous yeast species from Australian Hibiscus flowers. Can J Microbiol 45, 172-177.

Makimura, K., Tamura, Y., Kudo, M., Uchida, K., Saito, H. \& Yamaguchi, H. (2000). Species identification and strain typing of Malassezia species stock strains and clinical isolates based on the DNA sequences of nuclear ribosomal internal transcribed spacer 1 regions. J Med Microbiol 49, 29-35.

Mayser, P., Haze, P., Papavassilis, C., Pickel, M., Gruender, K. \& Guého, E. (1997). Differentiation of Malassezia species: selectivity of cremophor EL, castor oil and ricinoleic acid for $M$. furfur. $\mathrm{Br}$ J Dermatol 137, 208-213.

Midgley, G. (2000). The lipophilic yeasts: state of the art and prospects. Med Mycol 38, 9-16.

Page, R. D. M. (1996). TREEVIEW: an application to display phylogenetic trees on personal computers. Comput Appl Biosci 12, 357-358.

Scorzetti, G., Fell, J. W., Fonseca, A. \& Statzell-Tallman, A. (2002). Systematics of basidiomycetous yeasts: a comparison of large subunit D1/D2 and internal transcribed spacer rDNA regions. FEMS Yeast Res 2, 495-517.

Senczek, D., Siesenop, U. \& Böhm, K. H. (1999). Characterization of Malassezia species by means of phenotypic characteristics and detection of electrophoretic karyotypes by pulse-field gel electrophoresis (PFGE). Mycoses 42, 409-414.

Sugita, T., Takashima, M., Shinoda, T., Suto, H., Unno, T., Tsuboi, R., Ogawa, H. \& Nishikawa, A. (2002). New yeast species, Malassezia dermatis, isolated from patients with atopic dermatitis. J Clin Microbiol 40, 1363-1367.

Theelen, B., Silvestri, M., Guého, E., van Belkum, A. \& Boekhout, T. (2001). Identification and typing of Malassezia yeasts using amplified fragment length polymorphism $\left(\mathrm{AFLP}^{\mathrm{TM}}\right)$, random amplified polymorphic DNA (RAPD) and denaturing gradient gel electrophoresis (DGGE). FEMS Yeast Res 1, 79-86.

Thompson, J. D., Higgins, D. G. \& Gibson, T. J. (1994). CLUSTAL W: improving the sensitivity of progressive multiple sequence alignment through sequence weighting, position-specific gap penalties and weight matrix choice. Nucleic Acids Res 22, 4673-4680. 